\title{
Case for diagnosis
}

Lourenço de Azevedo Lima ${ }^{1}$

Ricardo Barbosa Lima ${ }^{1}$

Carlos José Martins ${ }^{1}$

\section{Natacha de Carvalho Mello Haddad ${ }^{1}$ Antonio Macedo D'Acri ${ }^{1}$}

DOI: http://dx.doi.org/10.1590/abd1806-4841.20142863

\section{CASE REPORT}

A 45-year-old white female presented with a 1year history of papular lesions, ulcerations, and scarring on the abdomen, back, and limbs. Six months after symptom onset, she developed nausea, vomiting, and weight loss of $15 \mathrm{~kg}$. The patient reported she had been admitted to hospital for abdominal pain and ascites at some time during the last 3 months. During this hospitalization, exploratory laparotomy and peritoneal biopsy were performed, with noncontributory findings.

Physical examination revealed scarring and ulcerations on the chest, back, and abdomen, as well as papules with a porcelain-white center, some with an erythematous halo, on the extremities (Figures 1 and 2).

Laboratory tests, including antinuclear and antiphospholipid antibody titers, were within normal limits. Histopathological examination of an upper extremity papula showed thrombosed vascular structures and scant inflammatory cells around the vessels (Figure 3). The patient was prescribed acetylsalicylic acid (300 mg/day), dipyridamole $(150 \mathrm{mg} /$ day), and enoxaparin (40 mg/day). Her condition improved during the first week of treatment, but she developed abdominal pain caused by a bowel perforation, and died of sepsis.

\section{DISCUSSION}

In view of the clinical and laboratory findings, we established a diagnosis of Degos disease (DD). DD, also known as malignant atrophic papulosis, is a rare occlusive vasculopathy of unknown etiology, characterized by infarcts in the dermis, gastrointestinal tract, central nervous system, and other organs. ${ }^{1,2,3,4}$ Two variants have been described: one benign, confined to the skin, and one malignant, with systemic involvement. ${ }^{1,5}$ The first case was reported by Köhlmeier in 1941. DD affects individuals across all age ranges, but is most common in white young adults; there is a 3:1 male-to-female predominance. ${ }^{1,2}$

There are several theories about the pathogenesis of the disease: coagulopathy, vasculitis, primary

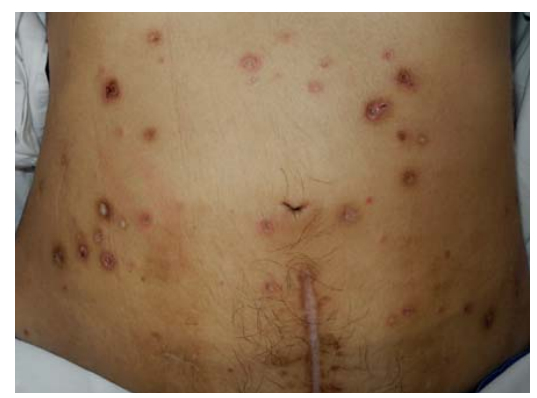

FIGURE 1: Multiple round scars and ulcerations on the abdomen, as well as an exploratory laparotomy scar

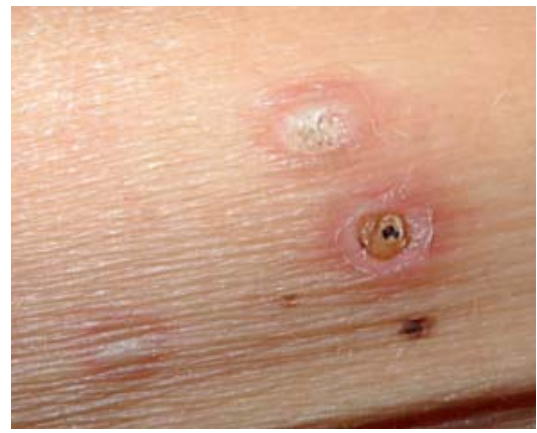

Figure 2: Scar with porcelainwhite center and ulcerated crusted lesion on the forearm, each with a halo of erythema

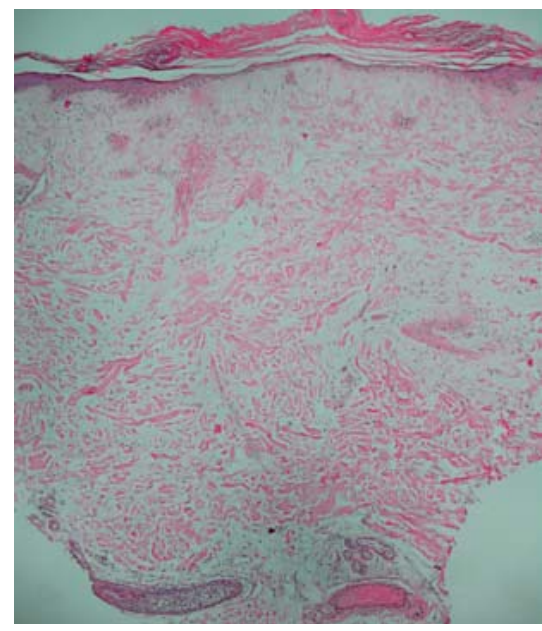

Figure 3

Skin biopsy s p e ci m e $n$. Epidermis: hyperkeratosis and atrophy of the stratum spi$\mathrm{n}$ o $\mathrm{s}$ u m. Dermis: localized necrobiosis with scant cells and absence of adnexal structures. Thrombo sed blood vessels are visible deep in the der$\mathrm{m}$ i s. ( H \& E stain, original magnification 40x)

\footnotetext{
Received on 11.06.2013.

Approved by the Advisory Board and accepted for publication on 30.07.2013.

* Work performed at the Department of Dermatology, Hospital Universitário Gaffrée e Guinle da Universidade Federal do Estado do Rio de Janeiro (UNIRIO) - Rio de Janeiro (RJ), Brazil.

Conflict of interest: None

Financial funding: None

Universidade Federal do Estado do Rio de Janeiro (UNIRIO) - Rio de Janeiro (RJ), Brazil.
}

(C2014 by Anais Brasileiros de Dermatologia 
endothelial cell disorder, and potential associations with collagen diseases, genetic factors, and viral infection (parvovirus B19). ${ }^{2,45,6}$ Recent studies suggest it is an endotheliopathy, mediated by C5b-9 deposition and increased cell expression of interferon alpha leading to vascular changes. ${ }^{7}$ Scheinfeld believes DD is a hematologic and/or endothelial condition, possibly attributable to an acquired, intrinsic genetic defect, and resembles paroxysmal nocturnal hemoglobinuria, a hematologic disease characterized by an alteration in the complement system that leads to intravascular hemolysis and thrombosis. ${ }^{5}$

The diagnosis of DD is mainly clinical. The appearance of the lesions varies according to the stage of disease progression. The initial lesions are round, pink papules, approximately $5 \mathrm{~mm}$ in diameter, which become umbilicated. In the chronic stage, these papules develop a porcelain-white central depression and a narrow, pink peripheral rim with fine telangiectasias. They are distributed predominantly across the trunk and limbs, and usually spare the scalp and pal- moplantar regions. ${ }^{2}$ The characteristic histological findings are wedge-shaped dermoepidermal necrosis and vascular thrombosis. ${ }^{8}$

DD affects several organs and systems, including the gastrointestinal tract, central nervous system, cardiopulmonary system, eyes, liver, and kidneys, usually after the onset of cutaneous lesions. ${ }^{1}$ Approximately 50 to $60 \%$ of patients with systemic symptoms die within 2 to 3 years, most due to gastrointestinal perforation. Neurologic and ocular manifestations occur in $20 \%$ and $13 \%$ of patients respectively. ${ }^{8}$

Several drugs have been used in $\mathrm{DD}$, including topical and systemic corticosteroids, azathioprine, methotrexate, ciclosporin, tacrolimus, mycophenolate mofetil, intravenous immunoglobulin, arsenic, sulfonamides, heparin, and warfarin, but none have produced satisfactory results. ${ }^{1}$ Recent studies suggest that eculizumab, an anti-C5 monoclonal antibody, may be a promising alternative. ${ }^{7}$

\begin{abstract}
Degos disease, also known as malignant atrophic papulosis, is a rare occlusive vasculopathy of unknown etiology characterized by infarcts in the dermis, gastrointestinal tract, central nervous system, and other organs. It is characterized by papules, which become umbilicated and evolve with a depressed porcelainwhite central area, with an erythematous halo with telangiectasias. Histological findings include wedge-shaped dermoepidermal necrosis and blood vessel thrombosis. Approximately 50-60\% of patients with systemic symptoms die within 2-3 years, most due to gastrointestinal perforation. We report a typical case, with lethal outcome, in a 45 -year-old woman.
\end{abstract}

Keywords: Complement C5; Malignant atrophic papulosis; Vascular diseases

\section{REFERENCES}

1. Chan NPY, Choi PCL, Leung CY. Malignant atrophic papulosis (Degos' disease). Hong Kong J Dermatol Venereol. 2008;16:27-33.

2. Leal R, Buffon LP, Georgakilas SMF, Gatti TR, Vidigal MR, Criado PR, et al. Papulose atrofiante maligna (doença de Degos). An Bras Dermatol. 2000;75:201-7.

3. Hohwy T, Jensen MG, Tøttrup A, Steiniche T, Fogh K. A Fatal Case of Malignant Atrophic Papulosis (Degos' Disease) in a Man with Factor V Leiden Mutation and Lupus Anticoagulant. Acta Derm Venereol. 2006;86:245-7.

4. Ball E, Newburger A, Ackerman AB. Degos' disease: a distinctive pattern of disease, chiefly of lupus erythematosus, and not a specific disease per se. Am J Dermatopathol. 2003;25:308-20.

5. Scheinfeld N. Commentary on Degos Disease A C5b-9/Interferon- $\alpha$-Mediated Endotheliopathy Syndrome by Magro et al: A reconsideration of Degos Disease as hematologic or endothelial genetic disease. Dermatol Online J. 2011;17:6.

6. High WA, Aranda J, Patel SB, Cockerell CJ, Costner MI. Is Degos' disease a clinical and histological end point rather than a specific disease? J Am Acad Dermatol. 2004:50:895-9.

7. Magro CM, Poe JC, Kim C, Shapiro L, Nuovo G, Crow MK, et al. Degos disease: a C5b-9/interferon- $\alpha$-mediated endotheliopathy syndrome. Am J Clin Pathol. 2011;135:599-610.

8. Ali YN, Hamed M, Azita N. Lethal systemic Degos disease with prominent cardiopulmonary involvement. Indian J Dermatol. 2011;56:564-7.

\author{
MAILING ADDRESS: \\ Lourenço de Azevedo Lima \\ Rua Mariz e Barros, 775 - Tijuca \\ 20270-004 - Rio de Janeiro - RJ \\ Brazil \\ E-mail:louarquivos@gmail.com
}

How to cite this article: Lima LA, Haddad NCM, Lima RB, D'Acri AM, Martins CJ. Case for diagnosis. Degos disease: a case report. An Bras Dermatol. 2014;89(3):521-2. 